\title{
Phenotypic characterization of mycobacteria isolates from tuberculosis patients in Kaduna State, Nigeria
}

\author{
${ }^{1,2}$ Ahmadu, I., ${ }^{1}$ Olonitola, O. S., ${ }^{1}$ Suleiman, A. B., ${ }^{3}$ Lawan, M. K., and ${ }^{4}$ Makolo, D. \\ ${ }^{1}$ Department of Microbiology, Faculty of Life Sciences, Ahmadu Bello University, Zaria, Nigeria \\ ${ }^{2}$ National Tuberculosis Reference Laboratory, Zaria, Nigeria \\ ${ }^{3}$ Department of Veterinary Public Health and Preventive Medicine, Faculty of Veterinary Medicine, \\ Ahmadu Bello University, Zaria, Nigeria \\ ${ }^{4}$ Department of Sciences, School of Preliminary Studies, Kogi State Polytechnic, Lokoja, Nigeria \\ Correspondence to: isiyakuadabka@yahoo.com
}

\begin{abstract}
:
Background: Tuberculosis (TB) remains one of the leading public health challenges in Nigeria and the burden is still high. There is hence a need for continuous characterization of mycobacteria to obtain current data that will aid the ongoing TB prevention and control programme. The aim of this study was to phenotypically characterize mycobacteria isolates recovered from clinical specimens of patients with tuberculosis in Kaduna State, Nigeria.

Methods: Two thousand, two hundred and twelve (2212) sputum samples were collected from patients clinically suspected to have TB in three different zones of Kaduna State, Nigeria, between May 2017 and October, 2018. Samples were processed by decontaminating with $\mathrm{NaOH}$-Citrate $\mathrm{N}$-acetyl-L-Cystein method for Ziehl Neelsen (ZN) AFB microscopy and culture on Lowenstein Jensen (LJ) slants which were incubated at $37^{\circ} \mathrm{C}$ for 8 weeks. Positive $\mathrm{LJ}$ cultures were further analyzed with a rapid TB antigen assay (SD-Bioline) to differentiate Mycobacterium tuberculosis complex (MTBC) from Non Tuberculous Mycobacteria (NTM).

Results: Out of the 2212 patients with suspected TB, 300 (13.6\%) were positive for AFB by microscopy with Zone A (Kaduna North) having the highest AFB positive cases of 169 (15.2\%). Of the 300 AFB positive samples, 272 (91.0\%) were culture positive on LJ medium, $18(6.0 \%)$ were culture negative and $10(3.0 \%)$ were culture contaminated. Result of the distribution of mycobacteria among infected patients within the study area revealed that $219(80.5 \%)$ were infected with MTBC, 42 (15.4\%) with NTM and $11(4.0 \%)$ with both MTBC and NTM.

Conclusion: A relatively high number of TB in the study area was caused by NTM. There is need for advanced diagnostic tools that can differentiate MTBC and NTM strains among TB patients in all TB Reference Laboratories in Nigeria.
\end{abstract}

Keywords: Phenotypic, Characterization, Tuberculosis, Mycobacteria

Received May 25, 2019; Revised July 24, 2019; Accepted July 26, 2019

Copyright 2019 AJCEM Open Access. This article is licensed and distributed under the terms of the Creative Commons Attrition 4.0 International License (http://creativecommmons.org/licenses/by/4.0), which permits unrestricted use, distribution and reproduction in any medium, provided credit is given to the original author(s) and the source.

\section{Caractérisation phénotypique d'isolats de mycobactéries provenant de patients atteints de tuberculose dans l'État de Kaduna, au Nigéria}

\author{
${ }^{1,2}$ Ahmadu, I., ${ }^{1}$ Olonitola, O. S., ${ }^{1}$ Suleiman, A. B., ${ }^{3}$ Lawan, M. K., et ${ }^{4}$ Makolo, D. \\ ${ }^{1}$ Département de microbiologie, Faculté des sciences de la vie, Université Ahmadu Bello, Zaria, Nigeria \\ ${ }^{2}$ Laboratoire national de référence sur la tuberculose, Zaria, Nigéria \\ ${ }^{3}$ Département de santé publique vétérinaire et de médecine préventive, Faculté de médecine vétérinaire, Université \\ Ahmadu Bello, Zaria, Nigéria \\ ${ }^{4}$ Département des sciences, École d'études préliminaires, École polytechnique d'État de Kogi, Lokoja, Nigéria
}

Correspondance à: isiyakuadabka@yahoo.com 


\section{Abstrait:}

Contexte: La tuberculose reste l'un des principaux problèmes de santé publique au Nigéria et le fardeau est encore lourd. Il est donc nécessaire de caractériser en permanence les mycobactéries pour obtenir les données actuelles qui aideront le programme de prévention et de contrôle de la tuberculose en cours. Le but de cette étude était de caractériser phénotypiquement les isolats de mycobactéries récupérés à partir d'échantillons cliniques de patients atteints de tuberculose dans l'État de Kaduna, au Nigéria.

Méthodes: Deux mille douze cent douze (2212) échantillons d'expectorations ont été prélevés chez des patients cliniquement suspects de tuberculose dans trois zones différentes de l'État de Kaduna, au Nigéria, entre mai 2017 et octobre 2018. Les échantillons ont été traités par décontamination au NaOH-citrate. Méthode $\mathrm{N}$-acétyl-L-Cystéine pour la microscopie AFB de Ziehl Neelsen (ZN) et culture sur des pentes de Lowenstein Jensen (LJ) qui ont été incubées à $37{ }^{\circ} \mathrm{C}$ pendant 8 semaines. Les cultures de LJ positives ont ensuite été analysées avec un dosage rapide de l'antigène de la tuberculose (SD-Bioline) afin de différencier le complexe Mycobacterium tuberculosis (MTBC) des mycobactéries non tuberculeuses (NTM).

Résultats: Sur les 2212 patients suspects de tuberculose, $300(13,6 \%)$ étaient positifs pour AFB par microscopie, la zone A (Kaduna North) présentant le plus grand nombre de cas positifs avec $169(15,2 \%)$. Sur les 300 échantillons AFB positifs, $272(91,0 \%)$ étaient positifs en culture sur le milieu $\mathrm{L}$, $18(6,0 \%)$ étaient négatifs en culture et 10 (3,0\%) étaient contaminés par la culture. Le résultat de la distribution des mycobactéries parmi les patients infectés dans la zone d'étude a révélé que $219(80,5 \%)$ étaient infectés par le MTBC, $42(15,4 \%)$ avec les NTM et $11(4,0 \%)$ avec les deux types de MTBC.

Conclusion: Un nombre relativement élevé de tuberculose dans la zone d'étude a été causée par les MNT. Il existe un besoin d'outils de diagnostic avancés permettant de différencier les souches de MTBC et de MNT parmi les patients atteints de tuberculose dans tous les laboratoires de référence pour la tuberculose au Nigeria.

Mots-clés: Phénotypique, Caractérisation, Tuberculose, Mycobactéries

\section{Introduction:}

Mycobacterium tuberculosis also known as the tubercle bacilli is a pathogenic bacterium of the genus Mycobacterium and the causative agent of most cases of tuberculosis $(1,2)$. First discovered in 1882 by Robert Koch, $M$. tuberculosis has an uncommon waxy layer on its cell surface (primarily mycolic acid) which makes the cell impervious to Gram staining, hence acidfast detection techniques are used for its identification in the laboratory $(3,4)$. Mycobacterium tuberculosis is a non-motile and non sporulating rod. In smears stained with carbol fuschin or auramine and examined under the light microscope, the tubercle bacilli typically appear as straight or slightly curved rods but depending on growth conditions and age of the culture, bacilli may vary in size and shape from short coccobacilli to long rods. The dimensions of the bacilli have been reported to be $1-10 \mu \mathrm{m}$ in length (usually 3$5 \mu \mathrm{m})$, and 0.2-0.6 $\mu \mathrm{m}$ in width $(5,6)$.

Tuberculosis (TB) has a long history. It had existed before the establishment of recorded history and has left its mark on human creativity, music, art, and literature. It has also influenced the advancement of biomedical sciences and healthcare and may have killed more persons than any other microbial pathogen $(7,8)$. This disease known in the past as the "White Plague" is an ancient disease. Recent genetic evidence suggests that even our remote hominid ancestors, who lived three million years ago, may have suffered from TB $(6,9)$.

Mycobacterium tuberculosis forms a complex that comprises members implicated in human tuberculosis. The complex comprises seven members; M. tuberculosis, Mycobacterium bovis, Mycobacterium africanum, Mycobacterium canettii, Mycobacterium microti, Mycobacterium caprae and Mycobacterium pinnipedii. Mycobacterium tuberculosis is the primary causative agent of human TB; $M$. bovis is responsible for bovine TB and includes the vaccine strain $M$. bovis BCG; $M$. africanum is the main causative agent of TB in West Africa (10) while M. canetti is a rare MTBC strain which produces smooth and glossy colonies, with all cases so far isolated from people who have been to the horn of Africa $(5,11) ; M$. pinnipedii has been shown to be responsible for TB in marine host while $M$. caprae is responsible for TB in goats and $M$. microti infects larger mammals. Mycobacterium tuberculosis as the predominant cause of human TB is the most successful of human bacterial pathogens, and is sometimes referred to as Koch's bacillus after the discoverer (12).

While the disease is preventable and curable, TB has remained a significant cause of morbidity and mortality in resource limited nations (13). Currently it has re-emerged in developed nations as well due to its synergy with human immunodeficiency virus/acquired immune deficiency syndrome, demographic changes and human migrations $(14,15)$. On the basis of tuberculin reactivity, one third of the world's population is believed to be infected with latent TB. These infected individuals are thus at risk of developing TB later in life as their immunity wanes from aging or HIV co-infection $(2,16)$ even as TB is a major opportunistic infection in HIV infected persons $(15,17)$. This study was thus carried out to characterize mycobacteria among presumptive TB patients at the three major TB reference hospitals in Kaduna State, Nigeria. 


\section{Materials and Methods:}

\section{Study area}

Kaduna State is located in the Northwest geo-political zone of Nigeria, lying between latitude $6^{\circ}$ and $11^{\circ}$ North and longitude $7^{\circ}$ and $44^{\circ}$ East, and is 608 meters above sea level. The study locations were Ahmadu Bello University Teaching Hospital Shika, National TB and Leprosy Training Centre Zaria and General Hospital Kafanchan in Giwa, Zaria and Jama'a Local Government Areas respectively (Fig.1).

\section{Study design and population}

The study is cross sectional, involving TB patients attending the Directly Observed Treatment Short Course (DOTS) clinics in the three senatorial districts of Kaduna State, Nigeria. Samples collected were from presumptive TB patients attending the DOTS clinics in the selected hospitals (Ahmadu Bello University Teaching
Hospital Shika; National TB Referral Hospital, Zaria, and General Hospital, Kafanchan).

\section{Sample size determination}

Sample size was determined by the formula, $N=t^{2} p q / d^{2} \quad(18)$, where $N=$ minimum sample size, $\mathrm{t}=$ standard normal distribution at $95 \%$ confidence interval (1.96), d=allowable error taken as $0.05, p=$ known prevalence rate of the infection, and $q=1-p$. The prevalence rate of NTM infection ( $p$ ) used was $15.5 \%$ (19), which gives a sample size of 201. To adjust for expected losses due to contaminated cultures, non-growth and other factors, the calculated sample size was increased by $20 \%(20)$ to 240 . However due to differences in the study locations, the sample size was increased to 300 . The proportion to size (PPS) sampling as recommended by the World Health Organization (21) was used to allocate sample size across the three selected hospitals.

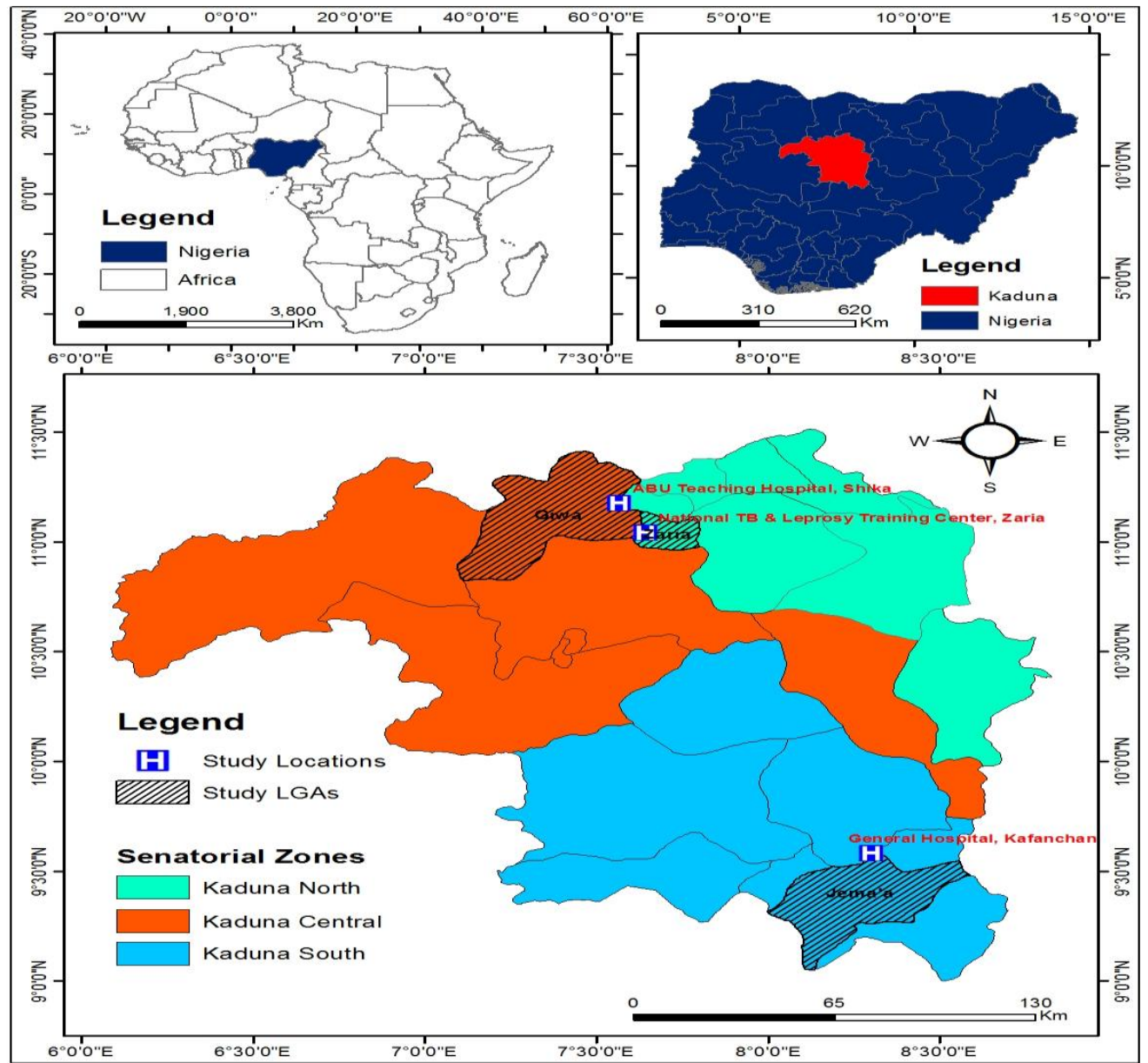

Fig. 1: Map of Africa, Nigeria and Kaduna State showing the study locations 


\section{Inclusion and exclusion criteria}

The inclusion criteria for the study are; new smear positive TB patients, willingness to participate through informed consent, and patients aged 15 years and above. Patients who were smear negative, those with confirmed drug resistant TB, those on re-treatment TB therapy, and those who did not give informed consent were excluded

\section{Ethical approval}

Ethical approval for this study was obtained from the State Ministry of Health, Kaduna State, Nigeria.

\section{Collection of demographic and clinical data} A structured questionnaire was used to collect demographic characteristics (age, sex, ethnicity, education, and marital status), health/behavioral factors (HIV, diabetes, smoking, alcohol use), environmental exposures (farming, animal contact, and dust season) and clinical variables (site, smear results) from each subject.

\section{Sputum sample collection}

One spot sputum sample was collected in a labeled standard screw-capped leak-proof sputum container with specific clinic identification and study numbers according to the National TB programme guidelines.

\section{Sputum transportation}

Sputum smear microscopy was performed at the study sites, and AFB smear positive specimens were transported in cold boxes packed with ice and thermometer (to monitor temperature) within 4 days of collection to the National TB Reference Laboratory by a courier company. Before transportation, the specimens were kept in a refrigerator at $2-8^{\circ} \mathrm{C}$.

\section{Culture of specimens}

All clinical specimens were processed in a Biological Safety Cabinet (BSC) using the NALC$\mathrm{NaOH}$ method as described by Steingart et al., (22). Equal volume $(5 \mathrm{ml})$ of NALC-NaOH and sputum were mixed. The mixture was vortexed and incubated for 15 minutes, and $35 \mathrm{ml}$ Phosphate buffer was added to the NALC-NaOH- sputum mixture and the tubes centrifuged at $4^{\circ} \mathrm{C}$ for 15 minutes at $3000 \times \mathrm{g}$. The supernatant was carefully discarded and the sediment was resuspended in $2 \mathrm{ml}$ buffer. Exactly $0.1 \mathrm{ml}$ of the sediment was inoculated into Lowenstein Jensen's (LJ) slants and incubated in $37^{\circ} \mathrm{C}$ incubator as described by Cadmus et al., (23). Smears were prepared from the portion of the sediment as described by Angra (24).

\section{Sputum microscopy}

The heat fixed smear was allowed to cool and stained with $1 \%$ carbol fuschin solution and heated from beneath by using spirit lamp until steam comes off from the stain. The stain was allowed to act on the smear for 10 minutes and the procedure was repeated 3 times. The slides were tilted to remove excess stain and washed gently with running tap water. Decolorization was done after rinsing the slides with water and flooded with 3\% acid alcohol for 2-3 minutes. The slides were then rinsed with water and flooded with $0.1 \%$ methylene blue for 1 minute. The slides were rinsed with water and allowed to air dry (25). The acid fast bacilli (AFB) load was recorded according to the International Union against Tuberculosis and Lung Disease (IUATLD) standard (26).

\section{Results:}

\section{Prevalence of mycobacteria by microscopy} Of the 2212 patients with suspected TB whose sputum were tested from the three Senatorial zones, 300 (13.6\%) samples were positive by AFB microscopy (Fig. 2)

\section{Distribution of mycobacteria by microscopy in the study area}

The result obtained showed that samples collected from Zone A (Kaduna North senatorial zone) National TB Reference Hospital, Saye-Zaria, had the highest number of TB positive cases of $169(15.2 \%)$ followed by Zone B (Kaduna Central Senatorial zone) ABUTH, Shika with 94 (13.4\%) and Zone C (Kaduna South Senatorial zone) General Hospital, Kafanchan with the lowest 37 $(9.3 \%)$ (Table 1) 


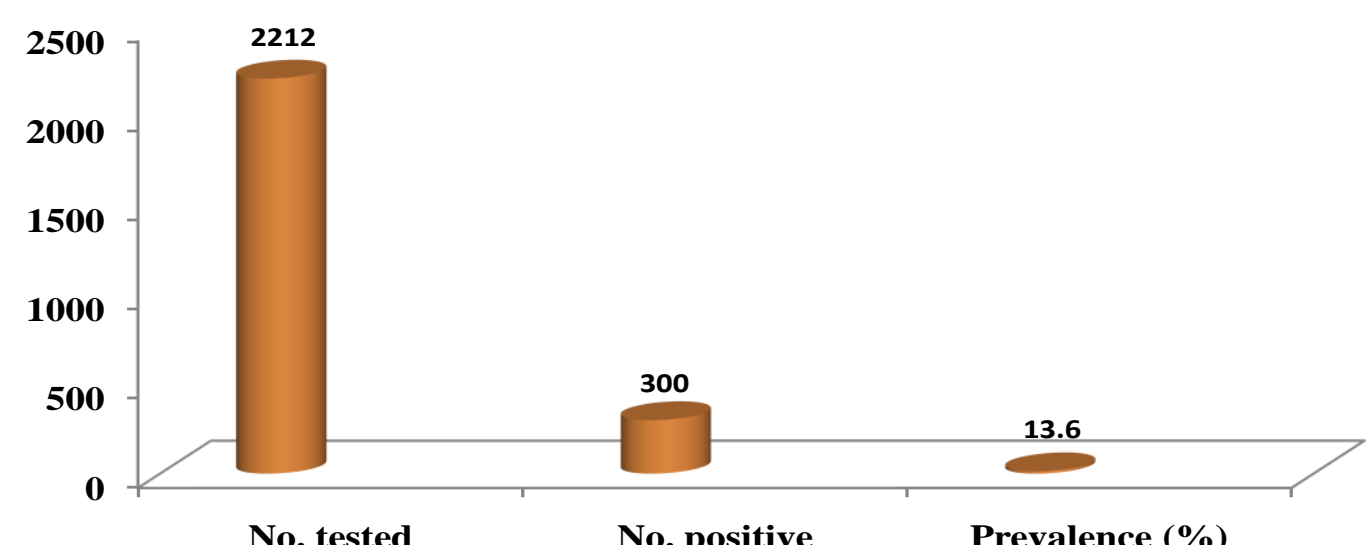

Fig.2: Prevalence of TB by microscopy among the study population

Table 1: Frequency distribution of TB by microscopy in the study area

\begin{tabular}{cccc}
\hline Study site & $\begin{array}{c}\text { Number of samples } \\
\text { collected }\end{array}$ & $\begin{array}{c}\text { Number of positive } \\
\text { samples }\end{array}$ & Prevalence (\%) \\
\hline Zone A (North) & 1112 & 169 & 15.2 \\
Zone B (Central) & 703 & 94 & 13.4 \\
Zone C (South) & 397 & 37 & 9.3 \\
Total & 2212 & 300 & 13.6 \\
\hline $\mathrm{X}^{2}=8.654, p=0.0132$ & & &
\end{tabular}

Table 2: Distribution of mycobacteria by culture on Lowenstein Jensen medium

\begin{tabular}{ccc}
\hline Culture result & Number of patient samples & Percentage (\%) \\
\hline Positive & 272 & 91.0 \\
Negative & 18 & 6.0 \\
Contaminants & 10 & 3.0 \\
Total & 300 & 100 \\
\hline
\end{tabular}

\section{Distribution of positive culture samples}

The percentage distribution of the 300 AFB positive samples based on culture on Lowenstein Jensen's ( $L J$ ) medium is shown in Table 2, with $272(91.0 \%)$ culture positive, 18 $(6.0 \%)$ culture negative and $10(3.0 \%)$ culture contaminated.

\section{Distribution of mycobacteria among culture positive participants}

The distribution of mycobacteria among the 272 culture positive participants is shown in Table 3 which revealed that MTBC were isolated in $219(80.5 \%)$, NTM in $42(15.4 \%)$ and co-infection of MTBC/NTM in $11(4.0 \%)$ participants. 
Table 3: Distribution of mycobacteria among the culture positive participants

\begin{tabular}{ccc}
\hline Mycobacteria & Number positive & Percentage (\%) \\
\hline MTBC & 219 & 80.5 \\
NTM & 42 & 15.4 \\
MTBC + NTM & 11 & 4.0 \\
Total & 272 & 100 \\
\hline MTBC $=$ Mycobacterium tuberculosis Complex, NTM = Non tuberculous Mycobacteria
\end{tabular}

\section{Discussion:}

In this study, the overall prevalence of TB by AFB microscopy among patients in Kaduna State was $13.6 \%$, and $12.3 \%$ by culture. The $13.6 \%$ rate is lower than the $18.6 \%$ reported by Aliyu (25) and $16.7 \%$ reported by Mamuda et al., (27). This lower prevalence rate may be due to the category of studied subjects but may also not be unconnected with the synergistic efforts of the stakeholders involved in the control of TB in Nigeria. The high (91\%) culture positive rate in AFB smear positive sputum obtained in this study may be due to the fact that samples were transported in cold chain and processed within the acceptable time limit in a high quality laboratory. Our culture positive rate is higher than the $85 \%$ rate reported by Selvakumar et al., (28) in India and close to the $100 \%$ rate reported by Simeon et al., (29).

Clinical specimens from non-sterile body sites such as sputum for TB culture are usually subjected to pre-treatment process involving digestion, homogenization, decontamination and concentration to eradicate more rapidly growing contaminants such as normal flora (other bacteria and fungi) without affecting the viability of the mycobacterial organisms that grow slowly (30). The contamination rate observed in our study was $3 \%$ and this low rate could be attributed to the fact that samples were processed and analyzed in high quality standard laboratory. This rate is within the acceptable range of WHO established standard of $3-5 \%$ for solid LJ culture method (31) and similar to those of Addo et al., (32) who reported $4.3 \%$ contamination rate. The contamination rate in our study is lower than Kassidy et al., (33) study in Uganda who reported high contamination rate of $31 \%$ for solid LJ medium, which is far above the recommended threshold of $5 \%$ for laboratories that receive freshly produced sputum samples. Our rate is also lower than those from studies in Nigeria and Zambia where reported contamination rates were $14.7 \%$ and $10.8 \%$ respectively $(19,34)$.

Smear positive but culture negative TB rate obtained from this study was $6 \%$. This could be attributed to dead acid fast bacilli or low number of viable bacilli undetected by $L J$ media or the killing action of $\mathrm{NaOH}$ used for decontamination. This rate is lower than that obtained by Mamuda et al., (26) in Nigeria with $8 \%$ and Addo et al., (35) in Ghana with $9.8 \%$.

The predominance of $M$. tuberculosis strains in our study is in agreement with studies from other African countries $(36,37)$. However, studies from other West African countries have reported a range of $9 \%$ to $28 \%$ of MTBC isolates to be $M$. africanum. Studies by Addo et al., (32), Niobe-Eyangoh et al., (36), Traore et al., (38) and Gomgnimbou et al., (39) have reported low prevalence of $M$. bovis in the African countries of Mali $(0.8 \%)$, Ghana $(3 \%)$, Burkina Faso $(0 \%)$ and Cameroun (0.2\%). Mycobacterium bovis infection mostly results from spread of livestock and or their products which may be transmitted through other routes than the respiratory system. The MTBC prevalence of $80.5 \%$ in our study is less than $91 \%$ reported by Addo et al., (32) in Ghana but similar to the study by Aliyu et al., (19) with prevalence rate of $85 \%$. The studies by Ani et al., (40) and Cadmus et al., (41) in Nigeria and USA reported lower rates of $69 \%$ and $48 \%$ respectively. The high prevalence of MTBC $(80.5 \%)$ in our study when compared to the prevalence of NTM $(15.4 \%)$ disagrees with the study of Muyoyeta et al., (34) who reported that in prevalence surveys, where mycobacterial speciation has been carried out, NTM may be three times more commonly found than MTBC in humans. This contradiction may be due to differences in environmental factors and control policies of animal movements and grazing activities in Nigeria.

The prevalence of $15.4 \%$ for NTM in this study is lower than the $39 \%$ reported in Ibadan by Cadmus et al., (41). The reason for this difference could be attributed to the lower sample size of only 23 patients used in the Ibadan study compared to 300 in the present study. Furthermore, our NTM prevalence is lower compared to the $23.1-26.6 \%$ rate reported in Northern Nigeria by Mawak et al., (42) and much lower than the prevalence of $56.9 \%$ reported in a study carried out in Taiwan by Chien et al., (43), but our rate is similar and comparable to the $16.5 \%$ recently reported in the south-south region of the country by Pokam and Asuquo (44) and $15 \%$ reported in a similar study by $\mathrm{Kim}$ et al., (45). The NTM prevalence in our study is however 
higher than the $11 \%$ previously reported by Idigbe et al., (46) in Lagos, a city in Southwestern Nigeria, and also higher than $11 \%$ recently reported by Borroni et al., (47) in Burkina Faso (a country in West Africa), Machado et al., (48) in Ontario Canada, and $6.4 \%$ reported by Wang et al., (49) in China, another vastly developing country but with an improved health care system compared to Nigeria.

The relatively high prevalence of NTM in our study may also be attributed to the fact that the study was conducted during both wet (rainy) and dry (harmattan) seasons. Harmattan is a West African trade wind that occurs during the winter and is characterized by heavy amount of dust in the air, low humidity, and reduced visibility (50). High risks for environmentally acquired pulmonary mycobacterial infections have been previously reported for individuals with occupational exposures to dust $(51,52,53)$. The prevalence of MTBC/NTM in this study was $4 \%$ which is lower than the report of Simeon et al., (29) who reported $13 \%$ from Ibadan. This might be due to the differences in sample size used in the studies but could also be due to varied sociodemographic and environmental factors.

\section{Conclusion:}

Based on the findings of this study, we conclude that an overall TB prevalence of $13.6 \%$ by AFB microscopy was obtained, with the highest rate of $15.2 \%$ in Zone $A$ (Kaduna South). This study also reported a high MTBC prevalence rate of $80.5 \%$ among patients seeking TB treatment but confirmed the occurrence of NTM in 15.3\% among the TB patients. Even though AFB microscopy permits a rapid identification of mycobacteria, it is not capable of distinguishing MTBC from NTM. This poses a great challenge to the TB control programme in Nigeria. Hence, inclusion of molecular screening assays that is capable of rapid detection of NTM infections in high burden resource limited settings should be a priority.

\section{Acknowledgments:}

We acknowledge the assistance of the management and staff of National TB Reference Laboratories Zaria, Ahmadu Bello University Teaching Hospital Zaria, and General Hospital Kafanchan for their contributions. The cooperation of all the patients who consented and participated in the study is acknowledged.

\section{References:}

1. Ismael K., and Ray, C. G. Sherries Medical Microbiology. Fourth edition, McGraw Hill, 2004

2. Amir, A., Rana, K., Arya, A., Kapoor, N., Kumar, H., and Siddiqui, M. A. Mycobacterium tuberculosis
H37Rv: In Silico Drug Targets Identification by Metabolic Pathways Analysis. Int J Evol Biol. 2014; 28: 41 - 70.

3. Albert, H., Manabe, Y., Lukyamuzi, G., Ademun, P., Mukkada, S., Nyesiga, B., and Perkins, M. D. Performance of three LED-based fluorescence microscopy systems for detection of tuberculosis in Uganda. PLoS One. 2010; 5: 12.

4. Yu, F., Lee, J., Wang, M., Hsu, H., Chen, T., Cheng, C., Yang, Y., Wang, G., and Yu, M. Evaluation of a modified direct agar proportion method for testing susceptibility of Mycobacterium tuberculosis from MGIT samples. J Microbiol Immunol Infect. 2014; 1182 (14): 15-21.

5. Alli, O. A. T., Ogbolu, D. O., Salawu, M. A., Oyedeji, J. G., Oladokun, L., and Obaseki, F. Molecular identification and prevalence of Mycobacterium tuberculosis complex amongst people living with HIV in Osun State, Nigeria. Afr J Clin Exper Microbiol. 2010; 11 (3): 138-145

6. Thumamo, B., Asuquo, A., Abia-Bassey, L., Lawson, L., Hill, V., Zozio, T., Emenyonu, N., Eko, F., and Rastogi, N. NIH Public Access. Infect Genet Evol. 2012; 4: 671-677.

7. Daniel, T. M. The History of Tuberculosis. Respir Med. 2006; 100: 1862-1870.

8. Kamala, R., Sinha, A., and Srivastava, A. Primary tuberculosis of the oral cavity. Indian J Dent. 2011; 22 (6): 835-838.

9. Guiterrez, M. C., Brisse, S., Brosch, R., and Omais, B. Ancient Origin and gene mosaicism of the progenitor of Mycobacterium tuberculosis. PLoS pathogen. 2005; 1 (1): 3-12.

10. Kallenius, G., Koivula, T., and Ghebremichael, S. Evolution and clonal traits of Mycobacterium tuberculosis complex in Guinea-Bissau. J Microbiol. 1999; 37: 3872 - 3878.

11. Pfyffer, G. E., and Funke, K. P. Comparison of the Mycobacteria growth indicator tube (MGIT) with radiometric and solid culture for recovery of acid fast bacilli. J Clin Microbiol. 1997; 35: 364-367.

12. Wang, M., and Chen, T. Copy of Tuberculosis, Past, Present and Future. J Respir Dis. 2013; 28 (12): 6871.

13. Corbett, E. L., Walker, C. J., Maher, D., Williams, B. G., Raviglione, M. C., and Dye, C. The growing burden of tuberculosis: global trends and interactions with the HIV epidemic. Arch Int Med. 2003; 163: 1009-1021.

14. Davies, P. D. The world-wide increase in tuberculosis: how demographic change, HIV infection and increasing numbers in poverty are increasing tuberculosis. Ann Med. 2003; 35: 235-243

15. Daftari, A., and Padayatchi, N. Social constraints to TB/HIV healthcare: accounts from co infected patients in South Africa. AIDS Care. 2013; 24 (12): 14801486.

16. Lilleback, T. A., Dirksen, I., Baess, B., Strunge, V. O., Thomsen, A., and Andersen, B. Molecular evidence of endogenous reactivation of Mycobacterium tuberculosis after 33 years of latent infection. J Infect Dis. 2002 ; 185: 401-404.

17. Raviglione, M. C., Snider, D. E. J., and Kochi, A. Global epidemic of tuberculosis. Morbidity and Mortality of a worldwide epidemic. JAMA. 1995; 220226.

18. WHO. Global tuberculosis Report. Available at http://www.who.int/tb/publications/global_report/en/. (2011). Accessed 14 ${ }^{\text {th }}$ May, 2012.

19. Aliyu, A., El-Kamary, S., Abimiku, A., Brown, C., Tracy, K., Hungerford, L., and Blattner, W. Prevalence of Non-Tuberculous Mycobacterial Infections among Tuberculosis Suspects in Nigeria. PLoS One. 2013; 8 (5): e63170

20. World Health Organization. Guidelines on tuberculosis http://www.who.int/publications/guidelines/tuberculos is/en/. Accessed $11^{\text {th }}$ October, 2013.

21. World Health Organization. Drug-resistant TB surveillance and response. Supplement global 
tuberculosis, 2014.

22. Steingart, K. R., Henry, M., Ng, V., Hopewell, P. C., Ramsay, A., Cunningham, J., Urbanczik, R., Perkins, M., Aziz, M. A., and Pai, M. Fluorescence versus conventional sputum smear microscopy for tuberculosis: a systematic review. Lancet Infect Dis. 2006; 6 (9): 570-581.

23. Cadmus, S. I. B., Palmer, S., Okker, M., Dale, J. Gover, K., Smith, N., Jahans, K., Hewinson, R. G., and Gordon, S. V. Molecular analysis of human and bovine tubercle bacilli from a local setting in Nigeria. J Clin Microbiol. 2006; 44 (1): 29-34.

24. Angra, P. Ziehl Neelsen Staining: Strong red on weak blue or weak red under strong blue? Inter J Tuber Lung Dis. 2007; 11 (11): 1160-1161.

25. Aliyu, M. S. Prevalence of Multi-Drug Resistant Mycobacterium tuberculosis (MDR-TB) in Kaduna State, Nigeria. Ph.D. Thesis. Department of Microbiology, Ahmadu Bello University, Zaria-Nigeria. 2015; $1-104$

26. International Union against Tuberculosis and Lung Disease (IUALTD) Technical Guide: Sputum Examination for Tuberculosis by Direct Microscopy in Low Income Countries. Paris, 2000.

27. Mamuda, K., Olonitola, O. S., Jatau, E. D., and Nicholas, E. Evaluation of Nitrate Reductase Assay for Detection of Multi-drug Resistant Mycobacterium tuberculosis among Patients at National Tuberculosis Reference Laboratory Zaria Nigeria. J Adv Med Pharm Sci. 2017; 14 (1): 1 - 7

28. Selvakumar, N., Silambuchelvi, K, Sekar, M. G., Sunder, A. S., Anbarasu, S., Rekha, V. B., Ponnuraja C., and Kumar, V. Quality indicators in a mycobacteriology laboratory supporting clinical trials for pulmonary tuberculosis. Int J Mycobact. 2012; 1 (4): 185-189.

29. Simeon, I. C., Bassirou,D., Brehima, T., et al. Non tuberculous Mycobacteria Isolated from Tuberculosis Suspects in Ibadan, Nigeria. J Pathog. 2016: 6547363. doi: 10.1155/2016/6547363.

30. Griffith, D. E., Aksamit, T., Brown-Elliott, B. A Catanzaro, A., Daley, C., and Gordin, F. An official ATS/IDSA statement: diagnosis, treatment, and prevention of non tuberculous mycobacterial diseases. Am J Respir Crit Care Med. 2003; 175: 367416.

31. Cornfield, D. B., Beavis, K. G., Greene, J. A., Bojak, M., and Bondi, J. Mycobacterial growth and bacteria contamination in the mycobacteria growth indicator tube and BACTEC 460 culture systems. J Clin Microbiol. 1997; 35 (8): 2068-2071.

32. Addo, K., Owusu-Darko, K., Yeboah-Manu, D. Caulley, P., and Minamikawa, M. Mycobacterial species causing pulmonary tuberculosis at the Korle $\mathrm{Bu}$ Teaching Hospital, Accra, Ghana. Ghana Med J. 2007; 41: 52-57.

33. Kassaza, K., Orikiriza, P., Llosa, A., Bazira, J., Nyehangane, D., Page, A. L., and Boum, Y. Lowenstein-Jensen selective medium for reducing contamination in Mycobacterium tuberculosis culture. J Clin Microbiol. 2014; 52 (7): 2671-2673.

34. Muyoyeta, M., Schaap, J. A., De Haas, P., Mwanza, W., Muvwimi, M. W., Godfrey-Faussett, P., and Ayles, $\mathrm{H}$. Comparison of four culture systems for Mycobacterium tuberculosis in the Zambian National Reference Laboratory. Int J Tuberc Lung Dis. 2009; 3 (4): 460-465.

35. Kennedy, K. A., Richard, O., Christian, B., Kwalu, O. Darko, Samuel, O. A., Gloria, I. M., Mercy, J. N., David, O. A., and Frank, A. B. First Nationwide Survey on the Resistance to First Line Anti-tuberculosis Drugs in Ghana. J Tuberc Res. 2018; 6 (1): 68-80.

36. Niobe-Eyangoh, S. N., Kuaban, C., Sorlin, P., et al. Genetic biodiversity of Mycobacterium tuberculosis complex strains from patients with pulmonary tuberculosis in Cameroon. J Clin Microbiol. 2003; 41: 2547-2553.

37. Korokoro, F., Kamdem, S. Y., Fotso, P. F., et al.
Population Dynamics of Tuberculous Bacilli in Cameroon as Assessed by Spoligotyping. J Clin Microbiol. 2013; 51: 299-302

38. Traore, B., Diarra, B., Dembele, B. P., Somboro, A. M., and Hammond, A. S. Molecular strain typing of Mycobacterium tuberculosis complex in Bamako, Mali. Int. J Tuberc. Lung Dis. 2012; 21: 543-557.

39. Gomgnimbou, M. K., Refregier, G., Diagbouga, S. P. et al., Spoligotyping of Mycobacterium africanum, Burkina Faso. Emerg Infect Dis. 2012; 18: 117-119.

40. Ani, A., Bruvik, T., Okoh, Y., et al., Genetic diversity of Mycobacterium tuberculosis Complex in Jos, Nigeria. BMC Infect Dis. 2010; 10: 189.

41. Cadmus, S. I., Diarra, B., Traore, B., Maiga, M., Siddiqui, S., Tounkara, A., Falodun, O., Lawal, W., Adewole, I. F., Murphy, R., Soolingen, D., and Taiwo, B. Non tuberculous mycobacteria isolated from tuberculosis suspects in Ibadan, Nigeria. J Pathog. 2016: Article ID 6547363. http://dx.doi.org/ $10.1155 / 2016 / 6547363$.

42. Mawak, J. D., Gomwalk, N. E., Bello, C. S. S., and Kandakai-Olukemi, Y. T. Human pulmonary infections with bovine and environmental (atypical mycobacteria) in Jos, Nigeria. Ghana Med J. 2006; 40: 132-136.

43. Chien, J., Lai, C., Sheng, W., Yu, C., and Hsueh, P. Pulmonary infection and colonization with non tuberculous mycobacteria, Taiwan, 2000-2012. Emerg Infect Dis. 2014; 20: 1382-1385.

44. Pokam, B. T., and Asuquo, A. E. Acid-fast bacilli other than mycobacteria in tuberculosis patients receiving directly observed therapy short course in Cross River State, Nigeria. Tuberculosis Research and Treatment. 2012; 1-4.

45. Kim, C. J., Kim, H., Song, N. H., et al. Differentiating rapid and slow-growing mycobacteria by difference in time to growth detection in liquid media. Diagn Microbiol Infect Dis. 2013; 75 (1): 73-76.

46. Idigbe, E. O., Anyiwo, C. E., and Onwujekwe, D. I. Human pulmonary infection with bovine and atypical mycobacteria in Lagos. J Trop Med Hyg. 1986; 89: 143-148.

47. Borroni, E., Badoum, G., Cirillo, D. M., Mattelli, A., Moyenga, I., Ouedraogo, M., Roggi, A., Saleri, N., Tagliani, E., and Tortoli, E. Mycobacterium sherrisii pulmonary disease, Burkina Faso. Emerg Infect Dis. 2015; 21: 2093-2095

48. Machado, D., Ramos, J., Couto, I., Cadir, N., Narciso, I., Coelho, E., Viegas, S., and Viveiros, M. Assessment of the BD MGIT TBC identification test for the detection of Mycobacterium tuberculosis complex in a network of mycobacteriology laboratories. Biomed Res Int. 2014: Article ID 398108.

49. Wang $H X$, Jun $Y$, Min $H A$, Yang JH, Gao RL, Jing $L$ J, Yang SS, Zhao YL. Non-tuberculous mycobacteria: susceptibility pattern and prevalence rate in Shanghai from 2005 to 2008. Chin Med J. 2010; 123 (2): 184187.

50. Weinstein, J. P., Hedges, S. R., and Kimbrough, S. Characterization and aerosol mass balance of PM2.5 and PM10 collected in Conakry, Guinea during the 2004 Harmattan period. Chemosphere. 2004; 78: 980-988.

51. Tiwari, R. R., Sharma, Y. K., and Saiyed, H. N. Tuberculosis among workers exposed to free silica dust. Indian J Occup Environ Med. 2007; 11: 61-64.

52. Corbett, E. L., Churchyard, G. J., Clayton, T. C., Williams, B. G., and Mulder, D. HIV infection and silicosis: the impact of two potent risk factors on the incidence of mycobacterial disease in South African miners. AIDS. 2000; 14: 2759-2768.

53. Mohapatra, H., Goswami, S., and Dey, D. Coalmine dust concentration and rate of tuberculosis infection around Ib Valley Coalfield, Orissa, India. Journal of Environmental Biology/Academy of Environmental Biology, India. 2010; 31: 953-956. 